\title{
COMPARTILHAMENTO DE CONHECIMENTO E COCRIAÇÃO: Um olhar a partir das práticas estratégicas da Revista Gestão em Análise (ReGeA)
}

\author{
Laodicéia Amorim Weersma \\ Universidade de Coimbra \\ laoweersma@gmail.com \\ Arnaldo Fernandes Matos Coelho \\ Universidade de Coimbra \\ acoelho@fe.uc.pt \\ Milton Shintaku \\ shintaku@ibict.br
}

Instituto Brasileiro de Informação em Ciência e Tecnologia

\section{Resumo}

Diante da crescente complexidade dos ambientes sociais, organizacionais e econômicos, a gestão do conhecimento torna-se essencial para o desenvolvimento, demandando estudos teóricos e práticos acerca de novos paradigmas que apontam o compartilhamento de conhecimento e a cocriação como ferramentas que tendem a integrar-se também aos ambientes acadêmicos e à ciência. Em tal cenário, este estudo tem como objetivo analisar a gestão de conhecimento, notadamente, a contribuição das práticas estratégicas de compartilhamento de conhecimento e de cocriação implementadas em novos periódicos nas fases de concepção e consolidação, à luz de critérios e de boas práticas de publicação científica. Para tanto, utilizase pesquisa de natureza descritiva com base em estudo de caso, cuja unidade de análise é a Revista Gestão em Análise (ReGeA). O trabalho é suportado por pesquisa-ação e observação participante desenvolvidas por seus editores. Os principais resultados evidenciam que as práticas de conhecimento compartilhado nos contextos de pesquisa e publicação cientifica proporcionam a geração de interações de alta qualidade, capacitando a cocriação e a construção de valor de forma criativa, intencional e integrativa, o que tende a trazer expressiva contribuição ao desempenho dos periódicos científicos nas fases de concepção e de consolidação, em termos de periodicidade, tempestividade e visibilidade. Além disso, pode-se perceber um aspecto de inovação com a participação dos stakeholders, que concretiza uma rede de conhecimento produtiva e sustentável, tornando-se crucial para melhorar a qualidade, a relevância e o impacto da pesquisa científica.

\section{Palavras-Chave}

Conhecimento compartilhado. Cocriação. Periódico Científico. Caso ReGeA.

\section{INTRODUÇÃO}

A sociedade contemporânea encontra-se sedimentada em processos complexos e dinâmicos, formando uma teia com atores que buscam o alcance de objetivos nos mais diversos contextos e perspectivas. A imprevisibilidade é uma realidade que se torna intensa diante dos avanços tecnológicos e rupturas constantes de status quo. Sendo assim, a gestão do conhecimento passa a ser uma importante prática que tende a reduzir incertezas e gerar subsídios à tomada de decisões.

Alinhados a tal perspectiva, Nonaka e Takeuchi (2008) argumentam que o conhecimento é criado dinamicamente, sintetizando o que aparentemente poderia 
ser considerado oposto ou contraditório. Forma-se por meio de uma espiral formada por socialização, externalização, combinação e internalização, em que perpassa por conceitos aparentemente opostos, como tácito e explícito, caos e ordem, micro (individuo) e macro (sociedade), espaço em que o raciocínio dialético transforma-se na chave para liderar tal processo. Segundo os autores, tornar o conhecimento pessoal disponível para os outros é a atividade central da empresa criadora de conhecimento.

Corroborando tal abordagem, Burnham (2002) ressalta que o conhecimento não nasce naturalmente da imanência do objeto ou do pesquisador, mas sim de uma construção no âmbito da alteridade, o olhar do outro. Esse entendimento vai de encontro aos argumentos de Sanders e Stappers (2008), os quais abordam a cocriação como um processo de criação conjunta e traz a ideia de criatividade coletiva, de um processo de troca entre pessoas que pode gerar diversos tipos de resultados. Esses processos participativos são descritos na literatura acadêmica, conforme argumentam Krucken, Mol e Mouchrek (2016), com nomenclaturas diversas e sob a perspectiva de várias áreas de conhecimento. De forma ampla, as autoras percebem que as abordagens participativas, que resultam da interação entre pesquisadores, trabalhadores, agentes de governo e comunidades locais, começaram a ser destacadas no âmbito da pesquisa acadêmica, especialmente na Escandinávia, Inglaterra, Holanda e Alemanha. Suas origens estão relacionadas a ações e desenvolvimento da sociedade e colaboração no trabalho, conforme destacam Nielsen e Nielsen (2006).

A partir de uma perspectiva mais abrangente, pode-se inferir que a cocriação de conhecimento em conjunto com ferramentas adequadas tendem a integrar-se também a ciência, tornando-se crucial para melhorar a qualidade, a relevância e o impacto da pesquisa acadêmica. Não obstante, iniciativas de cocriação de conhecimento, algumas vezes, carecem de medidas estratégicas para integrar e explorar parcerias que viabilizam resultados exitosos (MAUSER et al, 2013; TRENCHER; TERADA; YARIME, 2015).

Os processos de Difusão e Compartilhamento do Conhecimento (DCC) nas comunidades científicas e não científicas resultam em uma dinâmica permeada de desafios a serem vencidos (ANDRADE; RIBEIRO; PEREIRA, 2009). Muitos destes desafios estão sedimentados nas práticas culturais arraigadas ou em meras "tacanhas da razão" definidas como a luta de poder e o objetivo de publicar. Segundo Schugurensky e Naidorf (2004) e Machado (2005), essas questões estão vinculadas a autoridade e poder, sem focar no compromisso básico da universidade com a produção e divulgação da ciência.

Neste contexto, torna-se essencial a ampliação do debate acerca do processo de materialização da informação científica na forma de periódicos, já que esse processo de comunicação da ciência se constitui em um canal formal de registro e transmissão de conhecimento de forma durável e acessível. Tem-se a necessidade da discussão acerca de ações estratégicas a serem implementadas por novos periódicos que precisam atender aos requisitos básicos tais como tais como, registro no International Standard Serial Number (ISSN), qualidade, práticas éticas de publicação, periodicidade, tempestividade, disponibilização eletrônica e visibilidade (ARAÚJO et al, 2017; ANPAD, 2017).

Ampliando a discussão, Silva e Bitencourt (2018), bem como Nicholls, Simon e Gabriel (2015) sugerem que se desenvolva inovação voltada à oferta de soluções não apenas para problemas localizados, mas para questões mais sistêmicas e estruturais, o que sucita estudos que tratem de novos paradigmas metodológicos e conceituais (HOWALDT; DOMANSKI; KALETKA, 2016; PATIAS et al., 2017).

Em vista ao exposto, este estudo tem como objetivo analisar a gestão de conhecimento e, notadamente, a contribuição 
das práticas estratégicas de compartilhamento de conhecimento e de cocriação implementadas em novos periódicos nas fases de concepção e consolidação, à luz dos critérios de publicação científica e de boas práticas de publicação científica.

Para tanto, realiza-se uma pesquisa descritiva com base em estudo de caso, cuja unidade de análise é a Revista Gestão em Análise (ReGeA). O trabalho é suportado por pesquisa-ação e observação participante desenvolvidas por seus editores. Ademais, o artigo conta, além desta introdução, com uma base teórica acerca das características e requisitos dos periódicos científicos e das bases da gestão do conhecimento compartilhado e cocriação. As seções seguintes contemplam o método de pesquisa, a discussão dos resultados mediante o Caso da ReGeA para, finalmente, ser delineada a conclusão do estudo.

\section{CARACTERÍSTICAS E REQUISITOS DOS PERIÓDICOS CIENTÍFICOS}

Os periódicos científicos constituem um dos principais meios para disseminar o conhecimento produzido pelos pes $\neg$ quisadores, sendo fundamental na construção da ciência. Segundo Morais (CSE, 2017, prefácio, p. 12), “com a divulgação à comunidade, os resultados podem ser avaliados e utilizados. Com isso, permite-se que a sociedade tome conhecimento dos mesmos e do que estes representam para a coletividade".

Observa-se que os periódicos científicos, desde a sua criação no século XVII, na Europa, transformaram-se no canal preferencial de disseminação da informação científica, modernizando-se com o passar do tempo e adotando práticas, formatos mais adequados e, mais recentemente, deu-se início a transição do formato impresso para o digital. O que confirma a previsão de Hurd (2000) de que a comunicação científica em 2020 será eminentemente digital.

Em consonância com esse entendimento, Gulka (2016, p. 13) afirma que:
Mudanças nos suportes informacionais e nas diferentes formas de comunicação influenciaram toda a sociedade de modo global. A internet foi fator marcante nessas mudanças, à medida que interligou em rede não apenas as máquinas, mas também as pessoas. Nessa perspectiva, os periódicos se reinventaram como veículos que, aliados às Tecnologias da Informação e Comunicação, estão presentes no ambiente digital, o que culminou na criação de portais de periódicos.

No que tange aos editores dos periódicos científicos, segundo Diretrizes do Comitê de Política Editorial (CSE, 2017), estes possuem responsabilidades para com os autores, que produzem o conteúdo das publicações; os pareceristas, que avaliam os manuscritos; os leitores do periódico e a comunidade científica; as instituições que publicam e para com o público em geral. Além disso, é mister destacar que os periódicos são tipicamente propriedade de sociedades ou associações profissionais, fundações, universidades, hospitais, instituições de pesquisa, bibliotecas, organizações governamentais, organizações sem fins lucrativos ou editoras comerciais. Não obstante, tanto os pesquisadores como os responsáveis pelos periódicos devem, segundo Ferreira Junior (CSE, 2017), cumprir incessantemente as boas práticas em pesquisa, pautadas pela ética e com total respeito e responsabilidade sobre tudo aquilo que é publicado.

$\mathrm{Na}$ história dos periódicos científicos, questões técnicas como o formato dos artigos, periodicidade das revistas e composição da sua equipe de editoração foram se firmando. É possível que a validação do conteúdo por meio da avaliação pelos pares tenha sido o diferencial que passa a assegurar os critérios de qualidade. Vasconcellos (2017) afirma que a inspeção por pares (peer review) torna-se o elemento central dos periódicos científicos contemporâneos.

A cientificidade dos conteúdos a serem publicados, preferencialmente 
representados por artigos inéditos resultados de pesquisas originais, garante a primazia dos periódicos na disseminação do conhecimento. Outros tipos de manuscristos devem ser incluídos, de forma a garantir a pluralidade, como os artigos de revisão, ensaios, resenhas e outros, todos garantidos pela avaliação pelos pares, de preferência duplamente cega. A equipe editorial também deve ser preocupação da revista, na medida em que se deve evitar endogenia ou restrições temáticas. Mesmo que a revista seja de uma área específica, a equipe editorial (conselho e comitê) deve comporse de estudiosos renomados que atendam ao escopo da revista.

A política editorial, possivelmente, seja um dos fatores mais importantes da revista, visto que orienta todo o seu funcionamento, das questões técnicas até as de qualidade. No entanto, questões técnicas como a pontualidade e periodicidade passam a ser discutidas no cenário digital, requerendo ajustes nas políticas, assim como as questões envolvendo os direitos autorais, em frente ao movimento de acesso aberto.

Morais (CSE, 2017) ainda ressalta que os periódicos científicos são o meio mais confiável para a divulgação, pois se baseiam em regras específicas alinhadas com padrões éticos a fim de preservar a integridade na pesquisa. No âmbito internacional, Coelho et al. (2018) argumentam que muitos fatores, tanto qualitativos como quantitativos, são considerados na avaliação de periódicos para a inclusão nos índices emblemáticos da Coleção Principal da Web of Science: Science Citation Index Expanded (SCIE), Social Sciences Citation Index (SSCI) e Arts \& Humanities Citation Index (A\&HCI). Os autores argumentam que o processo de seleção de periódicos leva em consideração os seguintes aspectos: revisão por pares, práticas éticas de publicação, formato de publicação, cumprimento de periodicidade, convenções editoriais internacionais, existência de textos completos e em inglês.

Nesta direção, o Ministério da Educação (MEC) do Brasil, no âmbito da
Coordenação de Aperfeiçoamento de Pessoal de Nível Superior (Capes), no documento denominado de Considerações sobre Qualis Periódicos, nas áreas de Administração Pública e de Empresas, Ciências Contábeis e Turismo (Capes, 2017), definiu para a avaliação dos periódicos das referidas áreas os seguintes critérios: possuir ISSN, tempestividade, periodicidade, fontes de indexação e fator de impacto.

Nesse contexto, a Associação Nacional de Pós-Graduação e Pesquisa em Administração (ANPAD, 2017) elaborou o Manual de Boas Práticas da Publicação Científica com os seguintes requisitos:

- Ter registro ISSN;

- Informar, no sítio eletrônico e nas edições impressas (se houver), os dados das organizações responsáveis pela publicação;

- Apresentar, o sítio eletrônico, a missão do periódico, incluindo o foco temático, a política editorial e a menção explicita à adoção de avaliação por pares na forma de blind review ou pela revisão aberta;

- Informar os nomes completos e as respectivas afiliações institucionais do Editor, dos Editores Associados (se houver), do Editor Executivo (se houver) e de todos os integrantes do Comitê de Política Editorial e do Corpo Editorial Científico;

- Publicar, anualmente, na página ou portal de internet, e no último número de cada volume, para periódicos impressos, a lista daqueles que atuaram como revisores do periódico no ano, sem, no entanto, estabelecer uma ligação entre revisores e os manuscritos avaliados, a não ser que haja a opção pela avaliação por pares aberta;

- Disponibilizar permanentemente, no sítio eletrônico, as normas de submissão, com menção explícita aos idiomas de submissão e publicação oficiais do periódico, e a política editorial;

- Publicar, no mínimo, dois fascículos 
por ano, contendo documentos de caráter científico/tecnológico, inéditos e significativos para a área específica do periódico;

- Apresentar, no início de cada artigo: título, resumo e palavras-chave, no(s) idioma(s) em que for oferecido o texto e em inglês; e os nomes dos autores, com a respectiva afiliação institucional;

- Fornecer o endereço físico ou eletrônico de pelo menos um dos autores.

Diante da multiplicidade de diretrizes para a gestão de periódicos, é válido ressaltar o argumento de Sandes-Guimarães e Diniz (2014), que ratifica que para alcançar determinados objetivos é preciso o gerenciamento no fluxo editorial do periódico, em que as duas gestões, científica e administrativa, são interdependentes em um mesmo processo, gerenciado pelo editor científico, que busca efetuar a comunicação entre as partes no processo.

A gestão científica compreende o gerenciamento do processo de certificação de conteúdo do periódico, visando à seleção e à divulgação de conhecimento de qualidade, respaldada pelos atores envolvidos no processo. A gestão administrativa compreende o gerenciamento do processo de publicação de um periódico científico. [...] para isso, são necessárias diversas atividades, que envolvem resumidamente os processos de: produção editorial e gráfica (edição de texto, edição de layout, diagramação, impressão); gestão administrativa e financeira (gestão de pessoal, recursos financeiros, recursos materiais, acompanhamento de serviços terceirizados, etc) comunicação e marketing (indexação em base de dados, venda e distribuição) (SANDES-GUIMARÃES; DINIZ,
2014, p. 453).

Em vista desse contexto, a produção de conhecimento em grande escala aponta para a necessidade da disseminação e da aplicação do conhecimento. Acerca do assunto, Cremonezi, Spers e Oswaldo (2013) ainda argumentam que toda organização vivencia o ciclo do conhecimento (geração, criação, divulgação, compartilhamento e transferência) suscitando, de

\section{GESTÃO DO COMPARTILHAMENTO DE CONHECIMENTO E COCRIAÇÃO}

Desde o início dos anos noventa, o debate acerca do conhecimento torna-se uma das questões centrais tanto na academia como o entorno empresarial. Segundo Cherubini Neto (2006), além das antigas questões epistemológicas, novas indagações sobre a geração do conhecimento, sua avaliação, aquisição, armazenado e transmissão faz-se ampliar as discussões acerca da Gestão do Conhecimento (GC) em âmbito do cenário científico e econômico mundial.

$\mathrm{O}$ autor divide a GC em dois grandes grupos: Práticas de Gestão do Conhecimento e Ferramentas de Gestão do Conhecimento. As práticas de GC compreendem principalmente as práticas organizacionais e de gestão de pessoas destinadas à construção de um ambiente propício à criação ou geração, aquisição, transferência e compartilhamento do conhecimento. Já, as ferramentas de GC compreendem principalmente o uso das Tecnologias de Informação e Comunicação (TIC) voltadas à gestão do conhecimento

Entretanto, no contexto da gestão do conhecimento em periódicos científicos, para efeitos deste artigo, toma-se o estudo de Nonaka e Takeuchi (2008) como ponto de partida, no qual os autores apresentam quatro modos de conversão do conhecimento, conforme Figura 1. 
Figura $1-$ Espiral do conhecimento

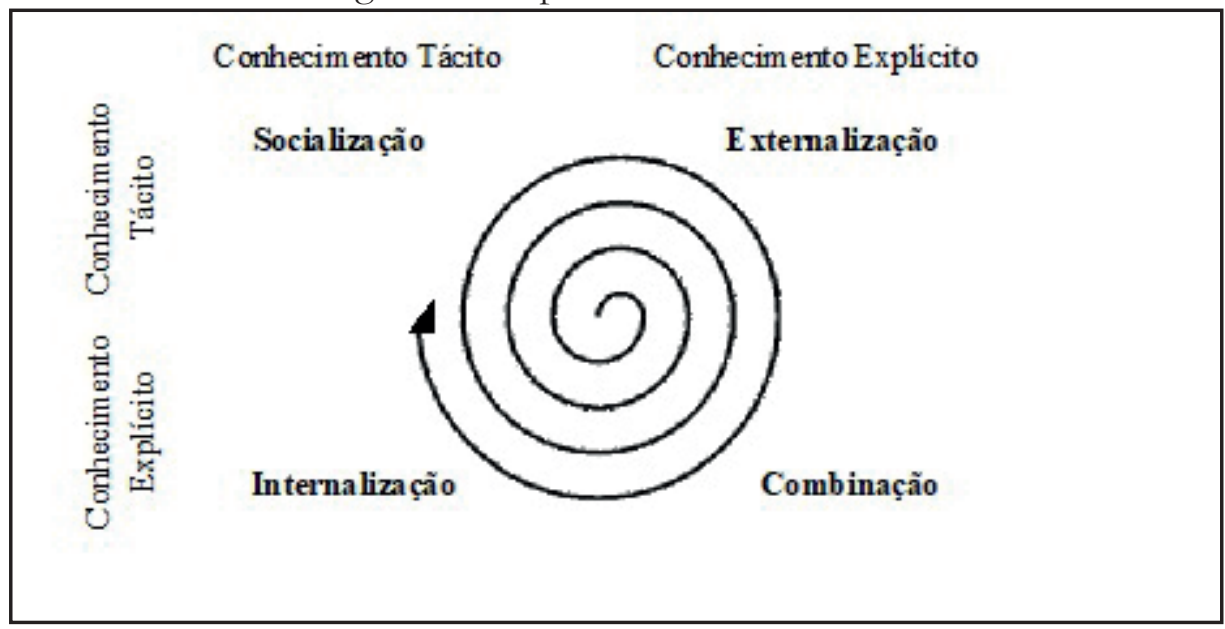

Fonte: Nonaka e Takeuchi (2008)

No Modelo de Espiral do Conhecimento de Nonaka e Takeuchi (2008), cada quadrante representa: i) Socialização - tipo de conversão resultante do compartilhamento de conhecimentos tácitos, ou seja, ocorre quando duas ou mais pessoas tornam comuns seus conhecimentos, decorre de troca de experiências entre elas; ii) Externalização - compartilhamento do conhecimento do sentido do tácito para o explícito, refere-se à transformação do subjetivo em objetivo; iii) Combinação - decorre da confrontação entre conhecimentos explícitos e está bastante próxima às práticas mais comuns das empresas, nas quais as pessoas compartilham conhecimentos objetivos e registrados e; IV) Internalização - processo de incorporação do conhecimento explícito no tácito.

Rosenberg (2002) relata ainda os benefícios que o gerenciamento do conhecimento pode trazer, sendo estes o aprendizado, a visão e a ação, a memória, a caixa de ferramentas, a criatividade e a integração. Cremonezi, Spers e Oswaldo (2013) argumentam que a gestão de conhecimento passa a ser traduzida pela rapidez com que se recebe as informações e essas causam um desafio à inteligência do indivíduo, obrigamno a usar o que sabe de forma correta. Esse processo engloba a geração, a criação, o armazenamento e o compartilhamento de informações valiosas e experiências de pessoas e organizações com interesses e necessidades parecidas e o ponto mais importante da gestão do conhecimento é o compartilhamento. Além disso, os autores ainda afirmam que para se constituir a gestão do conhecimento é necessário que existam pessoas talentosas, portadoras de conhecimento diferenciado e dispostas a compartilha-lo com outras pessoas.

Neste sentido, é importante observar a afirmação de Senge (2004) acerca do termo visão compartilhada, na qual o autor argumenta que esta surge a partir da visão pessoal que, combinada entre vários indivíduos, resulta em uma meta factível a ser alcançada. Argumentação esta que vai de encontro com as proposições de Andrade, Ribeiro e Pereira (2009) em que se tem o compartilhamento do conhecimento em direção ao coletivo. $\mathrm{O}$ cenário do conhecimento científico traz as redes e as tecnologias (pessoas, processos e tecnologias digitais) para uma função estratégica na geração e difusão da ciência, por permitirem inúmeras possibilidades de interações entre as diversas partes interessadas (pesquisadores, autores, editores, avaliadores e leitores), além da agilização do processo de comunicação.

Ressalta-se que o processo de compartilhamento envolve mais do que apenas 
coletar dados e informações e que, geralmente, o valor do conhecimento é expandido quando é compartilhado. Portanto, se gerenciado adequadamente, o compartilhamento do conhecimento pode melhorar muito a qualidade do trabalho e as habilidades de tomada de decisão, a eficiência na solução de problemas, bem como a competência que beneficiará o sistema como um todo (SYEDIKHSAN; ROWLAND, 2004; YANG, 2007).

Ainda vale mencionar que a noção de vantagem colaborativa está alinhada com a Visão Relacional - VR da estratégia (CROPPER et al, 2008), a qual possibilita a criação de uma fonte inimitável de recursos através de uma rede com acesso valioso a informações, compartilhamento de conhecimento, complementaridade de recursos, investimentos específicos de relacionamento e governança efetiva (BALESTRIN; VERSCHOORE; PERUCIA, 2014). E, em termos de estratégias coletivas, os autores sugerem que tais estratégias podem proporcionar três grupos distintos de recursos: i) Estrutura de colaboração como um recurso, em que relacionamentos com uma série de parceiros poderão proporcionar oportunidades únicas frente aos que não possuem tais relacionamentos; ii) Modo de relacionamento como um recurso, em que a qualidade de relacionamento entre os atores possibilitam uma maior confiança e um menor oportunismo, afetando o desempenho dos que integram a rede; iii) Parceiros como um recurso, quando a possibilidade de compartilhamento de conhecimento, de boas práticas e o acesso a soluções de problemas de forma coletiva, poderia gerar recursos exclusivos para os atores que rotineiramente se relacionam (SILVA; BITENCOURT, 2018, p. 16).

Não obstante, Cheng, Ho e Lau (2008) enfatizam que há duas formas não exclusivas de compartilhamento de conhecimento: i) Compartilhamento de rede fechada, no qual há compartilhamento de pessoa para pessoa e a liberdade de decidir o modo e a escolha de parceiros para compartilhar o conhecimento. Segundo os autores, esse tipo de interação permite um toque mais pessoal e esperase um compartilhamento mais direcionado, o que tende a explicar o sucesso dessa estratégia, incluindo o relacionamento pessoal e confiança; ii) Compartilhamento de rede aberta, no qual o compartilhamento dá-se através de um repositório central aberto, na qual o compartilhamento de conhecimento entre membros de um grupo dar-se por meio de um sistema de gerenciamento de conhecimento, geralmente um sistema de banco de dados central e envolve vários indivíduos compartilhando vários recursos de conhecimento no sistema.

Entretanto, a natureza do conhecimento científico é peculiar, bem como o ambiente no qual se dão os processos de sua criação, compartilhamento e uso, como destacam Leite e Costa (2006). As funções das universidades, de um modo geral, giram em torno da produção de conhecimento científico, sendo a sua comunicação processo fundamental para o ensino e a pesquisa. Esse ambiente acadêmico se constitui campo fértil para o estudo da GC. Contudo, para a sua disseminação e uso ótimos, o conhecimento científico necessita, além do sistema de comunicação, de mecanismos que garantam a efetivação desses processos. Segundo os autores, são necessários que sejam desenvolvidos e aplicados mecanismos que sejam capazes de auxiliar a Gestão do Conhecimento Cientifico - GCC. E toda e qualquer iniciativa nesse sentido não pode prescindir da comunicação científica, visto que a comunicação reside no coração da ciência, sendo tão vital quanto à própria pesquisa.

Sob esse olhar, Ramaswamy e Gouillart (2010) enfatizam que em indústrias intensivas em conhecimento, as práticas de inovação colaborativa já ocorrem e proporcionam a geração de interações de alta qualidade que, por sua vez, capacita a cocriação 
e tende a resultar em inovação e construção de valor de forma criativa, intencional e integrativa. Kotler, Kartajaya e Setiawan (2010) salientam que a cocriação descreve uma nova abordagem à inovação, já que envolve os stakeholders com atividades de colaboração que os une ativamente na concepção e desenvolvimento dessas inovações, trazendo uma perspectiva de desenvolvimento exógeno para endógeno dos projetos, em contraste com os processos internos e mais tradicionais. Portanto, é essa integração com os stakeholders, uma nova forma de cooperação, com benefícios simétricos e mútuos para as partes (WEXLER, 2011; MORAIS, 2014) que tente a se constituir em uma importante prática para a divulgação científica e, especificamente, para o novos periódicos científicos que necessitam se consolidar no ambiente de difusão do conhecimento e da pesquisa científica, objeto deste estudo.

\section{MÉTODO DE PESQUISA}

A pesquisa envolveu a condução de multimétodos de natureza qualitativa e finalidade descritiva. Inicialmente, temse uma pesquisa incrustada em um estudo de caso único, no qual a unidade de análise é a ReGeA. Acerca do assunto, Yin (2015) refere-se ao estudo de caso como sendo uma estratégia amplamente utilizada como método de pesquisa para a exploração de um sistema limitado ou de um caso, envolvendo uma coleta de dados em profundidade e com múltiplas fontes de informação, em determinado contexto. Utilizou-se de dados secundários provenientes dos arquivos da CPA da instituição responsável pelo periódico, bem como de informações provenientes do próprio portal que permite acesso aberto aos usuários, autores e comunidade cientifica e leitores que se interessam pela temática da revista.

O pilar central para o desenvolvimento do estudo de caso é a pesquisa-ação em conformidade com as proposições de Peruzzo
(2016), que argumenta que a pesquisa-ação tem sido fortemente aplicada para conhecer a realidade comunicacional e as dinâmicas de comunidades. Segundo a autora, o propósito da pesquisa-ação de contribuir para esclarecer e dar subsídios para a solução de problemas se alinha a geração de conhecimento capaz de ajudar na mobilização, no equacionamento das problemáticas e no empoderamento do processo de mudança do objeto em estudo.

Sob essa perspectiva, há de esclarecer que os autores deste estudo são os editores da ReGeA, objeto de estudo. De maneira resumida, segundo Gomes (2010), os editores são os responsáveis pelo gerenciamento de todo o processo de produção editorial de uma revista científica, cuja estratégia para a condução do desenvolvimento e consolidação do periódico está centrada em práticas de conhecimento compartilhado, sendo o cerne do objeto e objetivo deste estudo.

Sob esta perspectiva, pode-se ainda dizer que se utiliza de observação participante, conforme orientação de Minayo (2010) que define esta estratégia de pesquisa como um processo pelo qual se mantém a presença do observador numa situação social com a finalidade de realizar uma investigação científica, na qual o observador está em relação face a face com os observados. Ao participar da vida deles, no seu cenário cultural, colhe dados e se torna parte do contexto sob observação, ao mesmo tempo modificando e sendo modificado por este.

\section{O CASO DA REVISTA GESTÃO EM ANÁLISE (ReGeA)}

A ReGeA é um periódico cientifico para a divulgação de pesquisas nacionais e internacionais publicado pelo Centro Universitário Christus (UNICHRISTUS), vinculado aos cursos de Administração e Ciências Contábeis. É um veículo pluralista de divulgação dos resultados de pesquisas com 
temas convergentes com sua Linha Editorial disponível no Portal de Revistas link < http:// periodicos.unichristus.edu.br/index.php/ gestao/index>, com ISSN impresso 19847297 e com e-ISSN 2359-618X [online].

Publicada inicialmente em 2008 e com periodicidade anual, teve somente duas edições, mas que não apresentaram os requisitos necessários para sua inserção em bases indexadoras ou em algum tipo de repositório. E, como tende a ser comum aos novos periódicos, a ReGeA não atendeu a tempestividade satisfatória e parou a publicação em 2009. Quando, em 2014, o reitor da instituição convidou e empossou a nova editora executiva e, na sequência, foi indicado como editor-chefe internacional um professor doutor proveniente de uma universidade europeia de notoriedade científica (Universidade de Coimbra) com o intento de internacionalizar o periódico e ampliar a sua visibilidade, representando uma prática inicial de cocriação para atendimento dos requisitos necessários em conformidade com o Manual de Boas Práticas da Publicação Científica (2017).

Nota-se aqui que, logo no início, define-se um posicionamento estratégico claro acerca da visão de compartilhada do conhecimento na gestão do periódico, pois mesmo sendo uma revista ainda eminentemente jovem, definiu-se logo de inicio, além da Editora e do Editor Internacional, um Comitê de Políticas Editoriais de base endógena e passou a formar um Conselho Editorial com um forte viés exógeno.

Nesta fase inicial, tem-se ainda a elaboração de um Planejamento Estratégico que delineou como missão da ReGeA a publicação dos resultados de pesquisas científicas com o foco em fomentar e disseminar o conhecimento em administração e ciências contábeis, pautada em ética e compromisso orientados para a inovação dos saberes junto à comunidade acadêmica e à sociedade interessada em geral.

O escopo da revista passou a ter clara definição, cuja ênfase é a publicação de trabalhos de âmbitos nacional e internacional, versando acerca de diversos domínios do conhecimento em instituições privadas e públicas, notadamente: comportamento organizacional; marketing; produção e logística; gestão empreendedora e estratégica; gestão da informação e inovação; gestão socioambiental; gestão financeira e contábil alinhadas à governança corporativa, além de temas convergentes ao direito empresarial. Os estudos relatam os resultados de pesquisa, em andamento ou concluída, em conformidade com os seguintes gêneros de escrita: i) artigo; ii) ensaio ou; iii) estudo de caso e, mais recentemente, com uma seção nomeada de ciclo de debates, de acordo com as diretrizes disponíveis no site da revista.

Concomitante, os editores da revista passam a ter filiação na Associação Brasileira dos Editores Científicos (Abec) e a adquirir formação específica na área, ampliando o seu olhar para a democratização do saber. A participação nos cursos de formação e atualização promovidos pela associação representa, conforme afirmação da editora executiva do periódico, "o grande diferencial para o estabelecimento de um plano factível no sentido da consolidação do periódico tanto em âmbito acional como internacional".

Em vista a crescente demanda de manuscritos submetidos ao periódico, a equipe começa ser ampliada e passa a contar, em 2016, além da bibliotecária responsável pela normalização e inserção da revista em diretórios e bases indexadoras, de uma assistente editorial como o fim de facilitar o fluxo editorial da revista, de forma que não haja atrasos em suas publicações semestrais e o periódico mantenha seus indexadores. A Figura 2, contempla o fluxo atual, em 2018, da ReGeA. 
Figura 2 - Fluxograma Editorial ReGeA

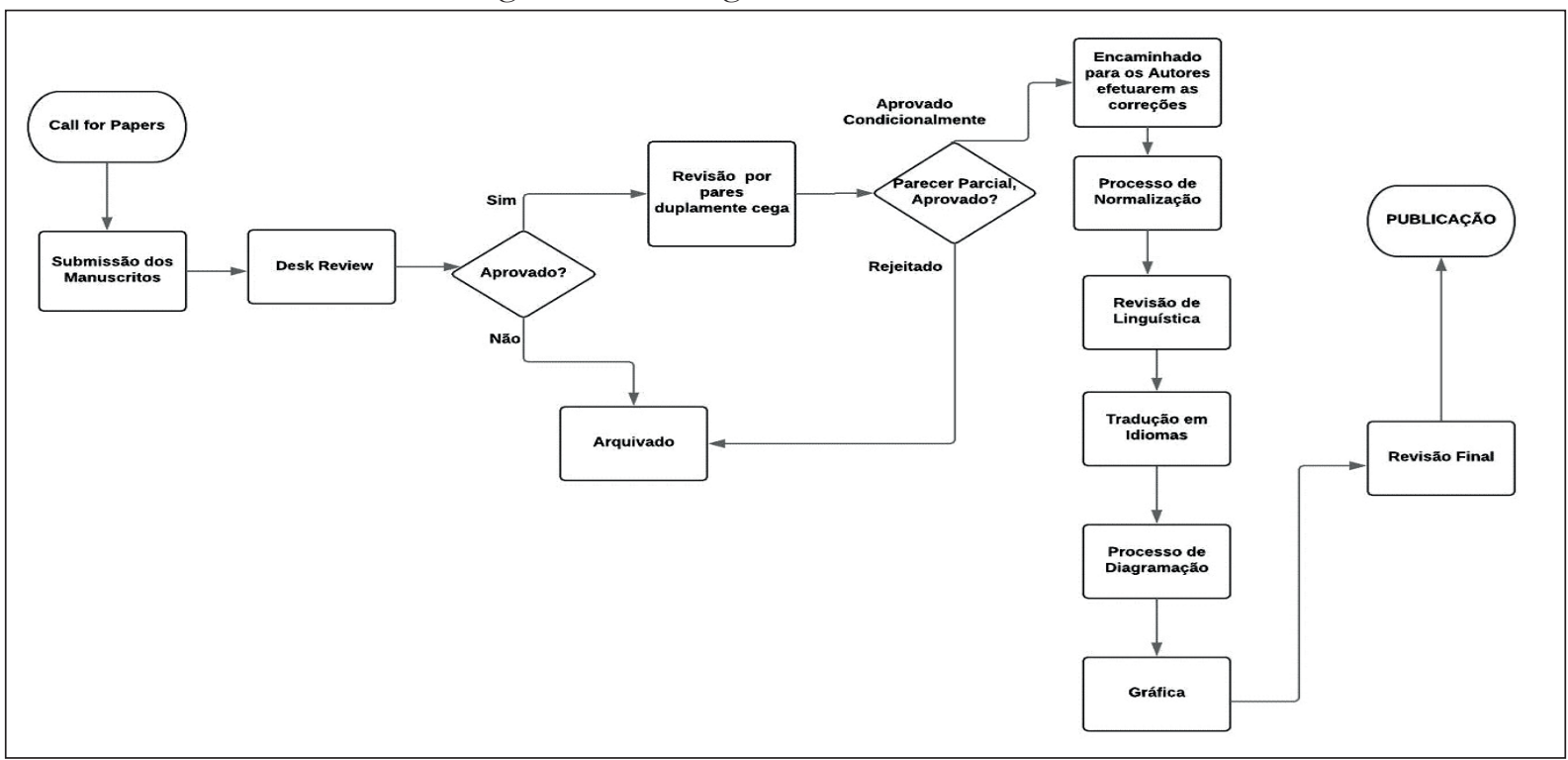

Fonte: Dados da pesquisa (2018)

Como o êxito do fluxo de publicação do periódico, passa-se a atender o Manual de Boas Práticas da Publicação Científica (ANPAD, 2017) com os seguintes requisitos: registro no ISSN; sítio eletrônico e nas edições impressas, os dados das organizações responsáveis pela publicação; disponibilização das normas de submissão, com menção explícita aos idiomas de submissão e publicação oficiais do periódico; a política editorial, bem como a missão do periódico, incluindo o foco temático, a política editorial e a menção explicita à adoção de avaliação por pares, na forma de blind review ou pela revisão aberta; informação dos nomes completos e as respectivas afiliações institucionais dos editores e dos integrantes do Comitê de Política Editorial e do Conselho Editorial; publicação anual da lista dos revisores que atuaram no periódico; publicação de dois fascículos por ano, contendo documentos de caráter científico e significativos para a área específica do periódico; apresentação no início de cada artigo do título, resumo e palavraschave, em português, espanhol e em inglês; os nomes dos autores, com a respectiva afiliação institucional e o endereço eletrônico dos autores.
Em vista disso, a ReGeA iniciou o processo de inserção em bases que proporcionam o open access. Para tanto, houve a integração ao Portal de Revistas Eletrônicas Open Journal Systems (OJS), sendo este um sistema que permite o acesso livre às publicações, bem como possibilita maior eficiência na gestão do processo editorial, já que confere transparência ao longo do processo, desde a submissão dos trabalhos online até o acompanhamento das fases de avaliação no sistema blind review e, sobretudo, o open access tende a aumentar a visibilidade da revista.

$\mathrm{Na}$ fase de consolidação, o periódico passa a fazer parte de diversas bases de indexação, dentre estas: i) Directory of Open Acess Journals (DOAJ) - serviço desenvolvido a partir da Universidade de Lund (Suécia), que pretende listar todas as publicações periódicas, de caráter acadêmico e científico, disponíveis em acesso aberto; ii) Sumários de Revistas Brasileiras, que tem como objetivo ampliar a divulgação e o acesso aos periódicos científicos nacionais; iii) Plataforma do Google Acadêmico, sendo esse um sistema de busca eletrônica de artigos científicos que oferece a possibilidade de encontrar informações atuais, fidedignas e 
revisadas por pares, elevando em muito a qualidade da informação disponível; iv) Red Iberoamericana de Inovação e Conhecimento Científico - REDIB - plataforma de agregação de conteúdos científicos e acadêmicos, em formato eletrônico, produzidos no âmbito ibero-americano e; v) EBSCO que mantém e distribui bancos de dados acadêmicos e indexadores de pesquisas a universidades e bibliotecas do mundo todo.

A revista passou a compor ainda diversos diretórios, dentre estes: i) Diretório de Políticas de Acesso Aberto das Revistas Científicas Brasileiras - DIADORIM, o qual faz parte do conjunto de serviços de acesso aberto do Instituto Brasileiro de Informação em Ciência e Tecnologia; ii) Sistema de informação das revistas de divulgação de investigação científica dos países da América latina, Caribe, Portugal e Espanha - LATINDEX ; iii) LIVRE - Revistas de Acesso Aberto, sendo um catálogo de livre acesso de todas as áreas de conhecimento vinculadas à Comissão Nacional de Energia Nuclear (CNEN) do Ministério da Ciência, Tecnologia, Inovações e Comunicações (MCTIC) do Brasil; iv) Repositório SHERPA/ RoMEO sendo este um serviço oferecido pela SHERPA para mostrar as políticas de depósito de obras com direito autoral e de acesso aberto das publicações acadêmicas, evidenciando o desenvolvimento de repositórios institucionais de acesso aberto nas universidades para facilitar a disseminação rápida e eficiente da pesquisa em todo o mundo e; v) Diretório SEER que objetiva a construção e gestão de publicação periódica eletrônica. Recomendado pela Capes, o processo editorial no SEER permite melhoria na avaliação da qualidade dos periódicos e maior rapidez no fluxo das informações; Diretório de indexação e cálculo do fator de impacto de periódicos internacionais de pesquisas científicas e finalmente - CITE FACTOR; o Diretório de Recursos Acadêmicos de Acesso Livre - ROAD.

O processo de consolidação do periódico tem sido fortemente impactado com a definição assertiva dos Membros do Conselho
Editorial, no qual se adota claramente a gestão de compartilhamento de conhecimento. E, a partir de 2018, passa a ser intensificado uma relação mais próxima de cocriação com os membros do Conselheiro Editorial, no sentido de convidar cada membro a ser editor de edição, passando a ReGeA, então, a contar com a função do Editor Convidado de Edição, que proporciona um posicionamento mais abrangente ao periódico em termos dos critérios de qualidade, tempestividade e visibilidade.

Ainda sob a égide da gestão compartilhada de conhecimento em direção ao coletivo, pontua-se o acordo de Cooperação Científica entre a Revista Gestão em Análise e a Rede InovaMundo. Para tanto, a editora executiva da ReGeA em conjunto com o editor científico e o fundador da Rede InovaMundo celebraram a parceria institucional, que consolida a nova seção do periódico denominada de "Ciclo de Debates InovaMundo", constituída por resenhas acompanhadas de notas de ensino.

É importante realçar que entre os anos 2014 a 2016, como resultado da gestão compartilhada e orientada por cocriação junto a seus stakeholders, a ReGeA foi classificada pela Capes, por meio do sistema de avaliação do Qualis Periódicos. Por este sistema, a Capes tem acesso às informações anuais que os programas de pós-graduação inserem na Plataforma Sucupira para identificar onde os pesquisadores estão publicando. Após ter esse conjunto de revistas no triênio, elas são divididas por estratos segundo critérios de cada comitê científico de área.

No caso especifico da ReGeA, no seu primeiro triênio de de gestão compartilhada do conhecimento e cocriação, 2014 - 2016, o periódico foi classificado em sete áreas distintas:

- Pública e de Empresas, Ciências Contábeis e Turismo - B3;

- Educação - B5;

- Interdisciplinar-B5; 
- Ciências Agrárias I - B5;

- Engenharias I-B5;

- Engenharias III - B5;

- Farmácia-C.

A composição do Conselho Editorial, em 2018, contou com a escolha de 44 membros externos, além do editor internacional, do editor de edição, do editor de seção e do analista editorial, em forma de rede fechada, em que há compartilhamento e cocriação. Tais práticas estão em conformidade com a proposição de Cheng, Ho e Lau (2008), na qual há a liberdade de decidir o modo e a escolha de parceiros para compartilhar o conhecimento.

Concomitantemente, há também o compartilhamento em rede aberta, através de um repositório central aberto, no qual o compartilhamento de conhecimento envolve vários indivíduos compartilhando vários recursos de conhecimento no sistema, o que também vai de encontro com as proposições de Cheng, Ho e Lau (2008). Essas práticas são refletidas em diversas ações, tais como a submissão dos autores pela plataforma SEER, desenvolvida no âmbito da Public Knowledge Project (PKP), uma iniciativa de universidades internacionais com o objetivo de investir em pesquisa e desenvolvimento de softwares livres para a melhoria da qualidade e do alcance de publicações acadêmicas. No Brasil, o uso da plataforma SEER é fomentado pelo Instituto Brasileiro de Informação em Ciência e Tecnologia (Ibict).

Além disso, tem-se ainda a utilização de redes sociais (fanpage no Facebook) cujo endereço é <https://www. facebook.com/revistagestaoemanalise $>$ com aproximadamente 1.002 pessoas que curtiram a página, posição de janeiro de 2019.

Em vista ao conjunto dessas práticas, tanto nas perspectivas fechada como aberta, a gestão implementada na ReGeA, alinhada com as práticas estratégicas de compartilhamento do conhecimento e cocriação, proporcionaram os seguintes resultados quantitativos no ano de 2018, conforme Quadro 1, a seguir.

Quadro 1 - Resultados quantitativos publicações, autores, avaliadores, indexadores e diretórios da

\begin{tabular}{|c|c|c|c|c|c|c|c|c|c|c|}
\hline \multirow{3}{*}{ Ano 2018} & \multirow{2}{*}{\multicolumn{2}{|c|}{$\begin{array}{l}\mathbf{N}^{\circ} \text { Trabalhos } \\
\text { Publicados }\end{array}$}} & \multicolumn{3}{|c|}{$\mathbf{N}^{\circ}$ AUTORES } & \multicolumn{3}{|c|}{$\mathrm{N}^{\circ}$ AVALIADORES } & \multirow{2}{*}{\multicolumn{2}{|c|}{$\begin{array}{l}\mathrm{N}^{\circ} \text { Indexadores } \\
\text { Diretórios }\end{array}$}} \\
\hline & & & \multirow{2}{*}{ Endógeno } & \multicolumn{2}{|c|}{ Exógeno } & \multirow{2}{*}{ Endógeno } & \multicolumn{2}{|c|}{ Exógeno } & & \\
\hline & Nac. & Int. & & Nac. & Int. & & Nac. & Int. & Index. & Diret. \\
\hline $1^{2}$ edição & 16 & 01 & 03 & 33 & 01 & 01 & 32 & 06 & 06 & 08 \\
\hline $\begin{array}{l}\text { TOTAL } \\
1^{2} \text { edição }\end{array}$ & \multicolumn{2}{|c|}{17} & \multicolumn{3}{|c|}{37} & \multicolumn{3}{|c|}{39} & \multicolumn{2}{|c|}{14} \\
\hline $2^{x}$ edição & 12 & 02 & 0 & 43 & 3 & 05 & 42 & 04 & 06 & 08 \\
\hline $\begin{array}{l}\text { TOTAL } \\
2^{2} \text { ediçãa }\end{array}$ & \multicolumn{2}{|c|}{14} & \multicolumn{3}{|c|}{46} & \multicolumn{3}{|c|}{51} & \multicolumn{2}{|c|}{14} \\
\hline
\end{tabular}

Fonte: dados da pesquisa, 2018

Em um contexto sistêmico, estes resultados de um periódico em fase de implantação, refletem o êxito da gestão da ReGeA em consonância às recomendações da Associação Nacional de Pós-Graduação e Pesquisa em Administração (ANPAD, 2017), em seu Manual de Boas Práticas da Publicação Científica. Há, ainda, conformidade com os critérios propostos pelo Ministério da Educação do Brasil, no âmbito da Capes, no documento denominado de 'Considerações sobre Qualis Periódicos, nas áreas de Administração Pública e de Empresas, Ciências Contábeis e Turismo' (Capes, 2017), que definiu para a avaliação dos periódicos das referidas áreas os critérios: possuir ISSN, tempestividade, periodicidade, fontes de indexação e fator de impacto. Cabe ainda acrescentar que 
os trabalhos que constituem a ReGeA, desde 2014, contêm o DOI e contam com fluxo de submissão contínuo.

\section{CONCLUSÃO}

A partir do estudo realizado, percebese a crescente complexidade dos ambientes, frente aos desafios cotidianos, seja em ambiente empresarial e tecnológico ou no ambiente puramente acadêmico e de pesquisa. Embora esses dois ambientes possuam características próprias, em ambas evidencia-se necessidade de acesso a conhecimentos, num processo de interseção conceitual da comunicação científica e organizacional.

Esse ponto tem destaque por meio dos periódicos científicos da área de conhecimento em administração, visto serem canais da comunicação científica, que disseminam muito conteúdos da comunicação organizacional. Comunicação científica e organizacional se alinham da produção e disseminação de conhecimentos que atendem as duas formas de comunicação, por meio da pesquisa em administração.

Assim, a ReGeA atende a disseminação de resultados de pesquisas, atendendo aos processos editoriais formados pela comunicação científica. Em muitos casos publica artigos voltados a gestão do conhecimento, base da comunicação organizacional, firmados pelas questões discutidas por Takeuchi e Nonaka (2009), ao tratar das questões do conhecimento tácito e explícito nas organizações.

No que tange a gestão da ReGeA, como um periódico científico, práticas colaborativas se fazem presentes, formando um novo paradigma norteado por geração de interações de alta qualidade, não apenas entre os atores relacionais ao processo de editoração, mas com o conhecimento publicado. Com isso, pode-se fomentar a cocriação de novos conhecimentos e práticas, que por sua vez tende a resultar na construção de valor de forma criativa, intencional e integrativa.

Neste cenário, o conhecimento tende a se mostrar cada vez mais como um diferencial de riquezas em qualquer área e as novas formas de gestão do conhecimento, notadamente de natureza compartilhada tornase uma das práticas essenciais, já que tendem a usar mais aspectos de criatividade e inovação, de modo que conduz a sustentabilidade, especialmente em periódicos científicos nas suas fases de concepção e de consolidação como evidenciados na ReGeA.

\title{
KNOWLEDGE SHARING AND CO-CREATION: A LOOK AT THE STRATEGIC PRACTICES OF THE JOURNAL OF MANAGEMENT ANALISYS (ReGeA)
}

\begin{abstract}
Faced with the growing complexity of social, organizational and economic environments, knowledge management becomes essential for development, provoking theoretical and practical studies about new paradigms that denote knowledge sharing and co-creation as tools that tend to integrate academic environments and science. In this scenario, the study aims to analyze knowledge management, notably the contribution of strategic practices of knowledge sharing and co-creation implemented in new periodicals in the phases of implementation and consolidation, in the light of criteria and good practices of scientific publication. To do so, a descriptive research based on a case study is used, which unit of analysis is the Journal of Management Analysis (ReGeA). The work is supported by action research and participant observation developed by its editors. The main results show that the practices of shared knowledge in scientific research and publication contexts provide the generation of high quality interactions, enabling creative and intentional creation and creation of value in a creative, intentional and integrative manner, which tends to bring significant contribution to the performance of scientific journals in the implementation and consolidation phases, in terms of periodicity, timeliness and visibility. In addition, the participation of the stakeholders can be seen as an innovative aspect, which materializes a network of productive and sustainable knowledge, becoming crucial to improve the quality, relevance and impact of scientific research.
\end{abstract}

\section{Keywords}

Knowledge sharing. Co-creation. Scientific Journal. Case study $\operatorname{ReGeA.}$ 
Artigo recebido em 15/01/2019 e aceito para publicação em 16/02/2019

\section{REFERÊNCIAS}

ANDRADE, Maria T. Tamanini; RIBEIRO, Núbia Moura; PEREIRA, Hernane Borges. Um estudo sobre a difusão e o compartilhamento do conhecimento na cultura acadêmica. In: REFERÊNCIAS

ANDRADE, Maria T. Tamanini; RIBEIRO, Núbia Moura; PEREIRA, Hernane Borges. Um estudo sobre a difusão e o compartilhamento do conhecimento na cultura acadêmica. In: CONGRESO ISKO-ESPAÑA, 9, Valencia, 2009. Anais... Valencia: ISKO, 2009.

ASSOCIAÇÃO NACIONAL de PÓSGRADUAÇÃO E PESQUISA EM ADMINISTRAÇÃO (ANPAD). Boas práticas da publicação científica: um manual para autores, revisores, editores e integrantes de corpos editoriais. Ed. 2. ANPAD, 2017.

ARAÚJO, Richard Medeiros; AZEVEDO, Alexandra K. de; VIEIRA, Leonor et al. Gestão de periódicos: um estudo na área de Administração, Ciências Contábeis e Turismo. Encontros Bibli: revista eletrônica de biblioteconomia e ciência da informação, v. 22, n. 49, p. 42-58, mai. 2017.

BALESTRIN, A.; VERSCHOORE, J. R.; PERUCIA, A. A Visão relacional da estratégia: evidências empíricas em redes de cooperação empresarial. BASE - Revista de Administração e Contabilidade da Unisinos, v. 11, n. 1, p. 47-58, jan./mar. 2014.

BURNHAM, Teresinha Fróes. Análise contrastiva: memória da construção de uma metodologia para investigar a tradução de conhecimento científico em conhecimento público. DataGramaZero Revista de Ciência da Informação, v. 3, n. 3, jun. 2002.

COORDENAÇÃO DE APERFEIÇOAMENTO DE PESSOAL DE NÍVEL SUPERIOR (Capes).
Considerações sobre Qualis Periódicos, nas áreas de Administração Pública e de Empresas, Ciências Contábeis e Turismo. 2017. Disponível em: <https://capes.gov.br/ images/Qualis periodicos 2017/Consideracoes Qualis Periodicos Area 272017 - final.pdf $>$. Acesso em: 01 jan. 2019.

CHERUBINI Neto, Reinaldo. As práticas e ferramentas da gestão do conhecimento auxiliam na gestão da interação universidade-empresa? Fundamentando e apresentando a hipótese. In: Encontro da ANPAD, 30, Salvador, Bahia, 2006. Anais... Salvador: ANPAD, set. 2006.

COELHO, Gabriel et al. Análise dos prazos de avaliação de artigos científicos dos periódicos da área de contabilidade no Brasil. Revista Mineira de Contabilidade, v. 19, n. 2, p. 31-43, maio/ago. 2018.

CREMONEZI, Graziela O. G.; SPERS, Valéria R. E.; OSWALDO Yeda C. Conhecimento e gestão do conhecimento científico: um estudo realizado junto a docentes de um curso de mestrado em administração. Revista Gestão Universitária na América Latina - GUAL, v. 6, n. 3, p. 169-189, 2013.

CROPPER, S.; EBERS, M.; HUXHAM, C.; RING, P.S. Introducing interorganizational relations. In: CROPPER, S.; EBERS, M.; HUXHAM, C.; RING, P. R. The Oxford Handbook of InterOrganizational Relations. New York: Oxford University Press, 533-554, 2008.

COUNCIL OF SCIENCE EDITORS (CSE). Diretrizes do CSE para promover integridade em publicações de periódicos científicos: atualização de 2012. Tradução e prefácio: Associação Brasileira de Editores Científicos. Botucatu, SP: ABEC, jul. 2017.

GOMES, Valdir Pereira. O editor de revista 
científica: desafios da prática e da formação. Informação \& Informação, v. 15, n. 1, p. 147172, jul./jun. 2010.

GULKA, Juliana Aparecida. Análise de presença digital: um estudo do portal de periódicos UFSC. 2016. 203 f. Dissertação (mestrado profissional em Gestão de Unidades de Informação) - Universidade do Estado de Santa Catarina, Florianópolis, SC, 2016.

HOWALDT, J.; DOMANSKI, D.; KALETKA, C. Social innovation: towards a new innovation paradigm. Revista de Administração Mackenzie, v. 17 , n. 6, p. 20-44, 2016.

HURD, Julie M. The transformation of scientific communication: a model for 2020. Journal of the Association for Information Science and Technology, v. 51, n. 14, p. 1279-1283, 2000.

KOTLER. P.: KARTAJAYA. H.: SETIAWAN. I. Marketing 3.0: as forças que estão definindo o novo marketing centrado no ser humano. Rio de Janeiro: Elsevier, 2010.

KRUCKEN, L.; MOL, I.; MOUCHREK, N. Cocriação no ensino de design: como desenvolver 'espaços projetuais' para inovação colaborativa?. Arcos Design, Rio de Janeiro, v. 9 n. 1, p. 27-50, jun. 2016.

LEITE, F. C. Lima; COSTA, Sely. Repositórios institucionais como ferramentas de gestão do conhecimento científico no ambiente acadêmico. Perspectivas em Ciênca da Informação, v. 11, n. 2, p. 206-219, mai./ago. 2006.

MACHADO J. A. S. Difusão do conhecimento e inovação: o acesso aberto a publicações científicas. In: Baumgarten, Maíra (Org.). Conhecimentos e redes: sociedade, política e inovação. Porto Alegre: UFRGS, 2005.

MAUSER W. et al. Transdisciplinary global change research: the co-creation of knowledge for sustainability. Current Opinion in Environmental Sustainability, v. 5, n. 3-4, p. 420-431, sep. 2013.
MINAYO, M. C. O desafio do conhecimento. São Paulo: Hucitec, 2010.

CHENG, Ming-Yu; HO, Jessica Sze-Yin; LAU, Pei Mey. Knowledge sharing in academic institutions: a study of multimedia university Malaysia. Electronic Journal of Knowledge Management, v. 7, n. 3, p. 313-324, 2008.

MORAIS, J. A co-criação, o crowdsourcing e a sustentabilidade aplicada à gestão e comunicação de marcas de moda. International Journal of Marketing, Communication and New Media, v. 2, n. 2, p. 105-118, jan./jun. 2014.

NICHOLLS, A.; SIMON, J.; GABRIEL, M. Introduction: dimensions of social innovation. In: NICHOLLS, A.; SIMON, J.; GABRIEL, M. (Org.). New frontiers in social innovation research. New York: Palgrave Macmillan, 2015.

NIELSEN, K. A.; NIELSEN, B. S. Methodologies in action research: action research and critical theory. In: NIELSEN, K. A.; SVENSSON, L. (Org.) Action research and interactive research: beyond practice and theory. Netherlands: Shaker Publishing, 2006.

NONAKA, I.; TAKEUCHI, H. Teoria da Criação do Conhecimento Organizacional. In: TAKEUCHI, H.; NONAKA, I. (Org.). Gestão do Conhecimento. Porto Alegre: Bookman, 2008.

PATIAS, T. Z.; GOMES, C. M.; OLIVEIRA, J. M.; BOBSIN, D. LISZBINSKI, B. B. Modelos de análise da inovação social: o que temos até agora?. Revista Brasileira de Gestão e Inovação, v. 4, n. 2, p. 125-147, 2017.

PERUZZO. Cicilia M.Krohling. Epistemologia e método da pesquisa-ação. Uma aproximação aos movimentos sociais e à comunicação. In: ENCONTRO ANUAL DA COMPÓS, 15, Goiânia, 7-10 jun. 2016. Anais... Goiânia: Compós, 2016.

RAMASWAMY, V.; GOUILLART, F. J. Building 
the co-creative enterprise. Harvard Business Review, October Issue, 2010.

ROSENBERG, Marc J. E-learning. São Paulo: Makron Books, 2002.

SANDERS, E. B. N.; STAPPERS, P. J. Co-creation and the new landscapes of design. CoDesign, v. 4, n. 1 , p. $5-18,2008$.

SANDES-GUIMARÃES, Luisa Veras de; DINIZ, Eduardo H. Gestão de periódicos científicos: estudo de casos em revistas da área de Administração. Revista de Administração, v. 49, n. 3, p. 449-461, jul./ago./set. 2014.

SCHUGURENSKY D.; NAIDORF, J. Parceria universidade-empresa e mudanças na cultura acadêmica: análise comparativa dos casos da Argentina e do Canadá. Educação e Sociedade, v. 25, n. 88, p. 997-1022, Especial, out. 2004.

SENGE, Peter. M. A quinta disciplina: arte e prática da organização de aprendizagem. São Paulo: Best Seller, 2004.

SILVA, Silvio Bitencourt da; BITENCOURT, Claudia. Gestão de recursos relacionais para o desenvolvimento de inovações sociais em living labs: o caso do habitat living lab de Vitória, ES Brasil. Revista Gestão em Análise, v. 7, n. 1, p. 13-30, 2018.

SYED-IKHSAN, S.O.; ROWLAND, F. Knowledge management in a public organization: a study on the relationship between organizational elements and the performance of knowledge transfer. Journal of Knowledge Management, v. 8, n. 2, p. 95-111, 2004.

TRENCHER, G.; TERADA, T.; YARIME, M. Student participation in the co-creation of knowledge and social experiments for advancing sustainability: experiences from the University of Tokyo. Current Opinion in Environmental Sustainability, 16 , p. 56-63, v. 16 , p. 56-63, oct. 2015.
VASCONCELLOS, Vinicius Gomes de. Editorial: a função do periódico científico e do editor para a produção do conhecimento no Direito e nas ciências criminais. Revista Brasileira de Direito Processual Penal. Porto Alegre, v. 3, n. 1, p. 9-17, jan./abr. 2017.

WEXLER, Mark N. Reconfiguring the sociology of the crowd: exploring crowdsourcing. International Journal of Sociology and Social Policy, v. 31, n. 1/2, p. 6-20, 2011.

YANG, J. The Impact of knowledge sharing on organizational learning and effectiveness. Journal of Knowledge Management, v. 11, n. 2, p. 83-90, 2007.

YIN, R. K. Estudo de caso: planejamento e métodos. 3. ed. Porto Alegre: Bookman, 2015.

*Versão revista e ampliada do Trabalho "Compartilhamento de conhecimento e cocriação: um olhar a partir das práticas estratégicas da revista gestão em análise (ReGeA)" apresentado no evento ABEC MEETING, 11-14, setembro, São Paulo, SP, 2018. 